\title{
A Review on JC Virus Infection in Kidney Transplant Recipients
}

\author{
Serena Delbue, ${ }^{1}$ Mariano Ferraresso, ${ }^{2,3}$ Luciana Ghio, ${ }^{4}$ Camilla Carloni, ${ }^{5}$ Silvia Carluccio, ${ }^{5}$ \\ Mirco Belingheri, ${ }^{4}$ Alberto Edefonti, ${ }^{4}$ and Pasquale Ferrante ${ }^{5,6}$ \\ ${ }^{1}$ Laboratory of Translational Research, Health Science Foundation "Ettore Sansavini", Corso Garibaldi 11, 48022 Lugo, Italy \\ ${ }^{2}$ Department of General and Vascular Surgery, St. Joseph Hospital, Via San Vittore 12, 20122 Milan, Italy \\ ${ }^{3}$ Department of Clinical Sciences and Community Health, University of Milan, Via Francesco Sforza 35, 20122 Milan, Italy \\ ${ }^{4}$ Pediatric Nephrology and Dialysis Unit, IRCCS Ca' Granda Foundation “Ospedale Maggiore Policlinico", Via Francesco Sforza 35, \\ 20122 Milan, Italy \\ ${ }^{5}$ Laboratory of Translational Research, Department of Biomedical, Surgical and Dental Sciences, University of Milan, Via Pascal 36, \\ 20133 Milan, Italy \\ ${ }^{6}$ Clinical Institute "Città Studi”, Via Ampere 47, 20133 Milan, Italy
}

Correspondence should be addressed to Mariano Ferraresso; mariano.ferraresso@unimi.it

Received 2 August 2012; Revised 3 January 2013; Accepted 3 January 2013

Academic Editor: Hans Hellmut Hirsch

Copyright (C) 2013 Serena Delbue et al. This is an open access article distributed under the Creative Commons Attribution License, which permits unrestricted use, distribution, and reproduction in any medium, provided the original work is properly cited.

The polyomavirus (PyV), JC virus (JCV), is a small nonenveloped DNA virus that asymptomatically infects about $80 \%$ of healthy adults and establishes latency in the kidney tissue. In case of immunodeficient hosts, JCV can lytically infect the oligodendrocytes, causing a fatal demyelinating disease, known as progressive multifocal leukoencephalopathy (PML). Although the reactivation of another human $\mathrm{PyV}, \mathrm{BK}$ virus (BKV), is relatively common and its association with the polyomavirus associated nephropathy (PyVAN) following renal transplantation is proven, JCV replication and its impact on graft function and survival are less well studied. Here we describe the biology of JCV and its pathological features and we review the literature regarding the JCV infection analyzed in the setting of transplantations.

\section{An Introduction to the Human Polyomavirus JC (JCV)}

JC virus (JCV) is a member of the Polyomaviridae family, including naked DNA viruses with icosahedral capsids and small, circular, and double-stranded DNA genomes. The natural hosts for polyomaviruses (PyVs) include humans, other primates, rodents, rabbits, and birds [1].

It was first isolated by Padgett et al. in 1971 from the brain of a patient with the initial JC, affected by Hodgkin's lymphoma who died of progressive multifocal leukoencephalopathy (PML), a demyelinating disease of the central nervous system (CNS) [2].

The 40-45 $\mathrm{nm}$ capsid is composed of three structural viral proteins, VP1, VP2, and VP3. The icosahedron consists of 72 pentamers, with no apparent hexamers, each composed by five VP1 molecules and one molecule of VP2 or VP3. The virion is formed of $88 \%$ protein and $12 \%$ DNA, represented by a single copy of supercoiled, circular, and double-stranded molecule of approximately $5.2 \mathrm{~kb}$, associated with cellular histone proteins $\mathrm{H} 2 \mathrm{~A}, \mathrm{H} 2 \mathrm{~B}, \mathrm{H} 3$, and $\mathrm{H} 4$ and packaged into chromatin resembling cellular genomes (minichromosomes) $[1,3,4]$.

The viral genome has a bipartite organization and contains two regions of about the same size, known as early and late transcription units, transcribed in opposite directions starting from a common hypervariable noncoding control region (NCCR), containing the origin of DNA replication (ori), the TATA box, cellular transcription factors binding sites, and bidirectional promoters and enhancers for the transcription of early and late genes. Starting from the NCCR, early transcription proceeds in a counterclockwise direction, while late transcription proceeds clockwise on the opposite strand of the DNA [5]. 


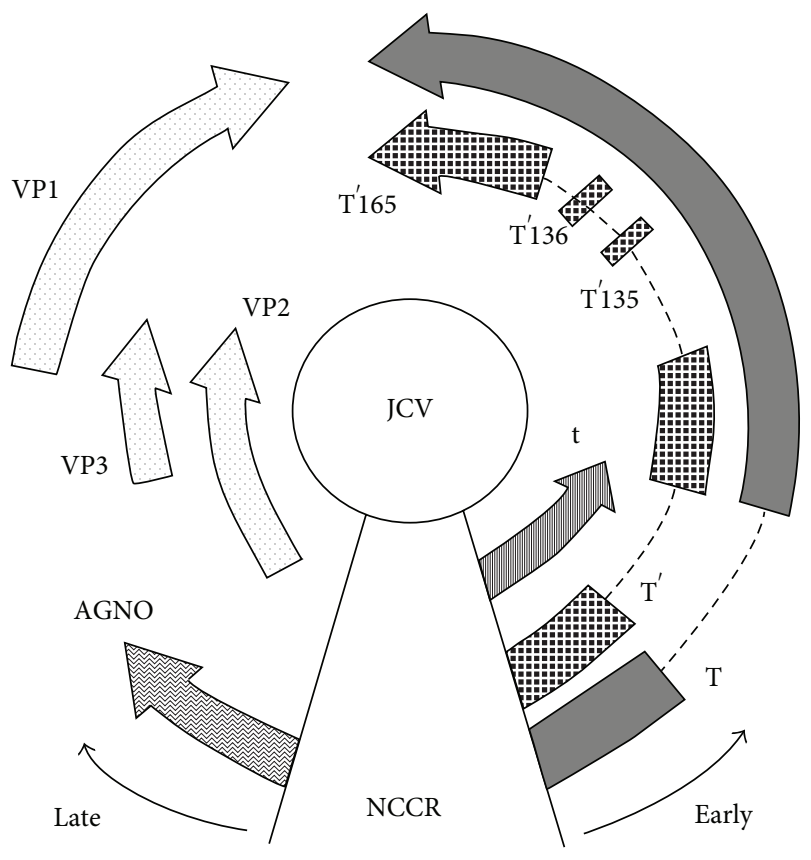

FIGURE 1: Schematic representation of the JCV genome organization. The circular, double-stranded DNA genome is $\sim 5.2 \mathrm{~kb}$ in size and is divided into the early coding region and the late coding region, transcribed in opposite directions from a common noncoding control region (NCCR). Early genes include large T antigen (T-Ag), small $t$ antigen $(t-A g), T^{\prime} 135, T^{\prime} 136$, and $\mathrm{T}^{\prime} 165$. Late genes include VP1, VP2, VP3, and agnoprotein.

The early region spans $2.4 \mathrm{~kb}$ and encodes the alternatively spliced transforming proteins, large tumor antigen (T$\mathrm{Ag}$ ) and small tumor antigen (t-Ag), which are involved in the viral replication and in promoting transformation of cells in culture and oncogenesis in vivo [5].

The late coding region spans $2.3 \mathrm{~kb}$ and encodes the capsid proteins VP1, VP2, and VP3 by alternative splicing of a common mRNA derived from the same primary late transcript and a small regulatory protein, known as agnoprotein, whose function in the virus life cycle is not completely clear [5] (Figure 1).

JCV does not infect any species other than humans and its ability to infect human cells may be restricted at the level of viral early gene transcription and DNA replication, with the T-Ag interacting specifically with the human DNA polymerase [6].

JCV has a tropism for replication in human glial cells, kidney epithelial cells, and, with a less efficiency, in B lymphocytes, and the restricted CNS tropism is confirmed by both experimental animals and in vitro analysis $[6,7]$.

The transmission of JCV is not fully understood. JCVspecific antibodies are detected in approximately $70 \%$ of adults [8] and the primary infection occurs in early childhood, usually in an asymptomatic way and results in a primary viremia. Afterwards, the virus produces a persistent latent infection in the kidney and is shed into the urine. In the context of an immunosuppressive condition, such as AIDS and transplantation, JCV disseminates to the CNS and lytically infects oligodendrocytes, causing the demyelinating disease, known as PML [9-11].

\section{Progressive Multifocal Leukoencephalopathy}

PML is a rare demyelinating disease characterized by the lytic infection of glial cells and is often fatal. The disease occurs almost exclusively in patients with severe immunodeficiency; consequently, the incidence of PML has increased dramatically, following the spread of HIV/AIDS. Nowadays, HIV infection is still the most frequent setting for PML, $~ 80 \%$ of the cases, followed by hematologic malignancies $(\sim 8 \%)$, solid cancers $(\sim 3 \%)$, organ transplantation, and autoimmune diseases treated with immunomodulators [12].

The classic form of PML is progressive and multifocal and involves the white matter. The main symptoms of the disease are motor deficits, altered consciousness, gait ataxia, and visual disturbances $[13,14]$. Atypical presentations of PML are increasingly recognized and include cerebellar syndrome, reflecting productive infection of granule cell neurons [15], meningitis [16], meningoencephalitis [17, 18], progressive myoclonic ataxia [19] and muscle wasting associated to extrapyramidal signs [20]. The median survival of PML patients without HIV infection is of few months, while in HIV positive patients subjected to highly active antiretroviral therapy (HAART) is longer but characterized by severe impairment of CNS. Indeed, successful treatments for PML are not currently available.

\section{JCV and Transplantation: Epidemiology}

Reports of JCV infection in renal transplant recipients have been published immediately after the first isolation of the virus $[32,33]$. Since those times, subsequent works have investigated both the silent and the symptomatic infection and/or reactivation of JCV in the setting of kidney transplantation, finding contradictory results. In 1980, Hogan et al. reported active infection after transplantation with JCV in about half of the 61 patients investigated [33]. Gardner and colleagues performed a wide prospective, serological study for the evidence of JCV infection in forty-eight renal transplant recipients, finding that $54 \%$ of the patients were seropositive already before the operation and that in $23 \%$ of the seronegative patients JCV infection occurred within the first three months after transplantation [34]. Molecular analyses were also conducted, by means of specific hybridization in situ, PCR, and quantitative PCR assays by different international groups: JCV has been identified in kidney biopsy tissue and/or urine within a range of 3.4\% and $46 \%$ of kidney transplanted patients (Table 1) [21-31,35]. The most recent surveys, that had the possibility to measure the amount of replicating JCV in the clinical specimens, reported also a very wide range of viral loads, from $2.0 \times 10^{3}$ copies $/ \mathrm{mL}$ to $1 \times$ $10^{7}$ copies/mL $[21,22,25,31,35,36]$. The association between the JCV viruria and transplantation has not been proved yet. In fact, Yin and colleagues showed that JCV load was markedly increased in transplant patients compared to the 
TABLE 1: Studies on JCV and kidney transplantation.

\begin{tabular}{|c|c|c|c|c|}
\hline Subjects $(n)$ & Sample & $\mathrm{JCV}(+) /$ subjects $(\%)$ & Pathological correlation & Reference \\
\hline \multirow{2}{*}{ KTx: 103} & Urine & $23 / 103(22.3 \%)$ & \multirow{4}{*}{ None } & \multirow{4}{*}[21]{} \\
\hline & Blood & 0/103 (0\%) & & \\
\hline \multirow{2}{*}{ Controls: 23} & Urine & $8 / 23(34.7 \%)$ & & \\
\hline & Blood & $0 / 23(0 \%)$ & & \\
\hline \multirow{2}{*}{ KTx: 103} & Urine & $28 / 103(27.2 \%)$ & \multirow{3}{*}{ None } & \multirow{3}{*}[22]{} \\
\hline & Blood & $15 / 103(14.2 \%)$ & & \\
\hline Controls: 0 & 1 & I & & \\
\hline \multirow{2}{*}{ KTx: 76} & Urine & $12 / 76(15.8 \%)$ & \multirow{3}{*}{ None } & \multirow{3}{*}[23]{} \\
\hline & Blood & $0 / 76(0 \%)$ & & \\
\hline Controls: 0 & 1 & I & & \\
\hline KTx: 68 & Urine & $14 / 68(21 \%)$ & \multirow{2}{*}{ None } & \multirow[t]{2}{*}[24]{} \\
\hline Controls: 0 & 1 & 1 & & \\
\hline KTx: 60 & Urine & $24 / 60(40 \%)$ & \multirow{2}{*}{ None } & \multirow{2}{*}[25]{} \\
\hline Controls: 60 & Urine & $11 / 60(18.3 \%)$ & & \\
\hline KTx: 186 & Urine & $33 / 186(17.8 \%)$ & \multirow{2}{*}{ None } & \multirow[t]{2}{*}[26]{} \\
\hline Controls: 0 & / & I & & \\
\hline \multirow{2}{*}{ KTx: 25} & Urine & $6 / 25(24 \%)$ & \multirow{3}{*}{ None } & \multirow{3}{*}[21]{} \\
\hline & Serum & $6 / 25(24 \%)$ & & \\
\hline Controls: 20 & Urine & $3 / 20(15 \%)$ & & \\
\hline KTx: 52 & Urine & $8 / 52(15.4 \%)$ & \multirow{2}{*}{ None } & \multirow{2}{*}[27]{} \\
\hline Controls: 30 & Urine & $0 / 30(0 \%)$ & & \\
\hline KTx: 59 & Urine & $2 / 59(3.4 \%)$ & \multirow{3}{*}{ None } & \multirow{3}{*}[28]{} \\
\hline CRD: 102 & Urine & $4 / 102(3.9 \%)$ & & \\
\hline Controls: 134 & Urine & $27 / 134(20.1 \%)$ & & \\
\hline KTx: 103 & Blood & 7/103 (6.8\%) & \multirow[t]{2}{*}{ None } & \multirow[t]{2}{*}[29]{} \\
\hline Controls: 0 & 1 & 1 & & \\
\hline KTx: 30 & Urine & $7 / 30(23.3 \%)$ & \multirow{2}{*}{ None } & \multirow[t]{2}{*}[30]{} \\
\hline Controls: 30 & Urine & $7 / 30(23.3 \%)$ & & \\
\hline KTx: 30 & Urine & $5 / 30(16.7 \%)$ & \multirow[t]{2}{*}{ None } & \multirow[t]{2}{*}[31]{} \\
\hline Controls: 0 & 1 & 1 & & \\
\hline
\end{tabular}

KTx: kidney transplant recipients; CRD: chronic renal diseases.

healthy group, confirming the association between immune function and viral levels [25]. On the contrary, Husseiny and colleagues observed a very low level JCV shedding in the urine of both normal subjects (15\%) and renal transplant recipients, with no differences among the viral loads [21]. Regarding JCV viremia in the renal transplant recipients, it seems to be very rare, transient, and low. In a cohort of 103 patients, it has been observed only in $14.2 \%$ of subjects with a mean viral load of $2 \times 10^{3}$ copies $/ \mathrm{mL}$; in another study conducted on 20 patients, $25 \%$ showed JCV viremia from the lower limit of detection (of 25 copies $/ \mathrm{mL}$ ) up to $10^{3}$ copies $/ \mathrm{mL}$ [21]. A long-term prospective follow-up study was conducted in France and JCV was detected in only 31 blood samples out of the 1487 collected [29].
Only few studies analyzed also the molecular features of the isolated virus, mainly observing that the JCV strains infecting the kidney transplantation recipients did not differ significantly from those infecting the immunocompetent subjects $[36,37]$. On the contrary, Yin and colleagues observed a dramatic increase in the proportion of transplant patients carrying two or more genotype strains of JCV compared with control subjects assuming an association between uncommon JCV genotypes and immunosuppression [25].

Regarding the nonkidney solid organ transplants (SOT), the incidence and clinical manifestation of JCV infection have been even more poorly investigated. In 2005, two independent groups published very different results about JCV infection in liver transplant patients, reporting $1.7 \%$ and 
$22.7 \%$ of patients excreting the virus, respectively [35, 38]. More recently, Kusne and colleagues [39] examined the frequency of JCV urinary shedding in a longitudinal study on 41 kidney and 33 liver transplant recipients. The proportion of patients shedding JCV was found higher in the liver than in the kidney transplant group (71\% versus $38 \%)$, with a viral load of $1.2 \times 10^{7}$ copies $/ \mathrm{mL}$ and $3.9 \times 10^{6}$ copies $/ \mathrm{mL}$, respectively. In addition, none of the patients with JCV viruria had also JCV viremia.

A prospective prevalence study on 100 liver transplant children reported a JCV viruria in $19 \%$, without clinical signs of viral infection. The viruria was not influenced by the extent of immunosuppressive therapy but it was found higher in pediatric liver transplant recipients [40] than reported in adult patients [41, 42].

Studies on the association between JCV infection and lung, pancreas and heart transplantations are very rare. Antonsson and colleagues [43] analyzed the seroprevalence and antibody stability of JCV in 441 organ transplant recipients, including 386 kidney, 9 heart, 1 kidney and heart, and 35 kidney and pancreas, over a time period of up to 18 months. The JCV seroprevalence was shown as $76 \%$ at baseline, higher than reported previously (reviewed in [43]), and it increased continuously over time reaching $80.4 \%$.

A previous study [38] on 263 heart, kidney, liver, and pancreas transplant patients reported JCV DNA in the blood for $2.7 \%$ of kidney, $0.04 \%$ of kidney pancreas, $1.1 \%$ of heart, and $0.8 \%$ of liver grafts, which was transient in $69 \%$ of the episodes. The majority of JCV DNAemic episodes were subclinical (61.5\%). Only 5 patients $(38.5 \%)$ had clinical symptoms at the time of JCV DNAemia, one out of which had biopsy-proven acute heart rejection, whereas the other four patients had fatigue, lethargy, dyspnea, or tremors. No patients developed manifestations of PML. Since the overall JCV DNAemia rate was 5\%, the authors remarked that JCV infection is a rare complication after SOT. JCV DNAemia was more common in kidney and/or pancreas transplant patients, possibly reflecting the reactivation of donor-derived JCV, which also persists in the kidneys [38]. These data were confirmed by Kamar and colleagues [44] that showed a higher JCV viremia in kidney (5.5\%) than in liver and heart rituximab-treated transplant patients.

Regarding JCV infections in lung transplant recipients, Thomas and colleagues [45] tested urine samples for the presence of JCV with conventional PCR, demonstrating a positivity rate of $24 \%$ in at least one urine specimens. Mean viral load analyzed with q-PCR was $5 \times 10^{5}$ copies $/ \mathrm{mL}$. However, there was no significant association between the immunosuppressive regiment and $\mathrm{PyV}$ infection. In fact, the prevalence of chronic graft dysfunction was $42 \%$ and $53 \%$ in patients who shed JCV or not, respectively. In addition, there was no significant correlation between urinary viral load and the patient's age and sex, the patient's immunosuppressive regimen, and the number of month after transplantation.

Although the different experimental approaches and the various results reported by the analyzed studies, they all agree that a strict attention should be paid to monitoring JCV infection, especially during the first 24 months following transplantation. In fact, even if JCV replication was mostly silent, it was not ruled out the hypothesis that it could be associated with certain clinical syndromes, as reported in Section 4.

\section{JCV and Kidney Transplantation: The Virus-Associated Diseases}

Infection by JCV has been observed in renal allograft recipients as both nephropathy and/or PML. PML occurs rarely in renal transplant patients and it is typically caused by JCV with high levels of viral genome found in the CSF (reviewed in [46]). However, recent reports suggest that another PyV, $\mathrm{BKV}$, can also cause a PML-like disease $[47,48]$.

Renal transplant recipients have the highest risk of developing polyomavirus associated nephropathy (PyVAN) in comparison to other organ recipients because of the presence of ongoing graft injury due to drug toxicity, rejection episodes, cold ischemia, and donor/recipients HLA mismatch [49-52]. PyVAN with graft dysfunction and premature graft loss has been markedly increased since the 1990s [53, 54]; therefore, a pathogenic potential of JCV should be taken into account. In contrast to the closely related BKV, to date, only few cases of nephropathy have been attributed to JCV [55-59]. Low level of JCV replication and shedding are common in immunocompetent individuals $[60,61]$ but surprisingly the incidence of asymptomatic viruria is not increased in renal allograft recipients $[62,63]$. This suggests that immunosuppressive state is not as strictly related to the development of PyVAN as it is for BKV $[64,65]$. In addition, the immunosuppressive regimen does not play any important role and, once JCV PyVAN has been established, the reduction of immunosuppression has a controversial impact on the clinical course [66]. However, a profound immunosuppressive state is required for a pathological and potentially threatening JCV replication. In fact, patients with PML have significant JCV viruria and PML and JCV PyVAN have been reported to occur concurrently [58, 67-70]. This raises the question whether anti-CD20 biological therapy with rituximab in kidney transplant recipients is potentially cumbersome, because of a rapid depletion of pre-B and mature $B$ cells that lasts for at least six months upon its administration. Our recent report in a small cohort of pediatric kidney transplant recipients showed that rituximab treatment had no effect on susceptibility to JCV replication [36]. These findings confirm some reports on adult population treated with either rituximab [71] or different immunomodulator drugs such as natalizumab $[72,73]$, where the risk of JCV new infection or reactivation was found inconsistent.

In a recent paper by Drachenberg and colleagues based on urine cytology and prospective protocol kidney biopsy in a cohort of hundred kidney transplant recipients, the incidence of JCV PyVAN was reported as low as $0.9 \%$ despite the fact that a significant proportion of the patients displayed JCV viruria or decoy cell shedding [22]. Interestingly, the majority of JCV PyVAN was diagnosed in patients with a normal renal function suggesting an apparently less aggressive or more protracted clinical course when compared with BKV PyVAN. This was recently confirmed by Cheng et al. in 
a larger cohort of kidney transplant recipients where the clinical outcome of JCV viruric patients was reported to be favorable up to five years following transplant [74]. Compared to non-JCV viruric patients, rejection rate, graft survival, and death-censored graft survival were lower and the patient survival was similar. Based on their results, they also suggested that JCV reactivation occurs in the native kidney on immunosuppression rather than in the donor-derived graft in contrast to BKV [52]. Another important difference between BKV PyVAN and JCV PyVAN is the strong association with viremia and the severity of histological pattern in the former [75]. On the contrary, low level of JCV viremia has been reported either in patients shedding large amounts of JCV in urine or in patients with parenchymal involvement and this may be related to fundamental differences between BKV and JCV biology, which remain presently unexplained $[26,38]$.

\section{Conclusion}

In conclusion, very few studies have been published regarding the replication of JCV in transplant patients. However, it is clear that JCV PyVAN is a unique clinical entity that needs to be differentiated from BKV PyVAN. This requires viral typing methods that are not widely available and this should account for an underestimation of its incidence in kidney transplant recipients. However, the protracted and nonaggressive clinical course of the disease and the favorable outcome should be considered once this form of PyVAN is diagnosed. Thus, monitoring of JCV infection, especially during the first 24 months after transplantation, is recommended.

\section{References}

[1] M. J. Imperiale, "The human polyomaviruses: an overview," in Human Polyomaviruses: Molecular and Clinical Perspective, $\mathrm{K}$. Khalili and G. L. Stoner, Eds., chapter 5, pp. 53-71, John Wiley \& Sons, New York, NY, USA, 2001.

[2] B. L. Padgett, D. L. Walker, G. M. ZuRhein, R. J. Eckroade, and B. H. Dessel, "Cultivation of papova-like virus from human brain with progressive multifocal leucoencephalopathy," Lancet, vol. 1, no. 7712, pp. 1257-1260, 1971.

[3] N. Ahsan and K. V. Shah, "Polyomaviruses: an overview," Graft, vol. 5, pp. 9-18, 2002.

[4] N. Ahsan and K. V. Shah, "Polyomaviruses and human diseases," Advances in Experimental Medicine and Biology, vol. 577, pp. 1$18,2006$.

[5] K. Khalili and M. K. White, "Human demyelinating disease and the polyomavirus JCV," Multiple Sclerosis, vol. 12, no. 2, pp. 133$142,2006$.

[6] K. Khalili, L. Del Valle, J. Otte, M. Weaver, and J. Gordon, "Human neurotropic polyomavirus, JCV, and its role in carcinogenesis," Oncogene, vol. 22, no. 33, pp. 5181-5191, 2003.

[7] G. V. Raj and K. Khalili, “Transcriptional regulation: lessons from the human neurotropic polyomavirus, JCV," Virology, vol. 213, no. 2, pp. 283-291, 1995.

[8] A. Egli, L. Infanti, A. Dumoulin et al., "Prevalence of polyomavirus BK and JC infection and replication in 400 healthy blood donors," Journal of Infectious Diseases, vol. 199, no. 6, pp. 837846, 2009.
[9] E. T. Clayson, L. V. J. Brando, and R. W. Compans, "Release of simian virus 40 virions from epithelial cells is polarized and occurs without cell lysis," Journal of Virology, vol. 63, no. 5, pp. 2278-2288, 1989.

[10] G. Perez-Liz, L. Del Valle, A. Gentilella, S. Croul, and K. Khalili, "Detection of JC virus DNA fragments but not proteins in normal brain tissue," Annals of Neurology, vol. 64, no. 4, pp. 379387, 2008.

[11] R. Caldarelli-Stefano, L. Vago, E. Omodeo-Zorini et al., "Detection and typing of JC virus in autopsy brains and extraneural organs of AIDS patients and non-immunocompromised individuals," Journal of Neuro Virology, vol. 5, no. 2, pp. 125-133, 1999.

[12] E. S. Molloy and L. H. Calabrese, "Progressive multifocal leukoencephalopathy: a national estimate of frequency in systemic lupus erythematosus and other rheumatic diseases," Arthritis and Rheumatism, vol. 60, no. 12, pp. 3761-3765, 2009.

[13] J. R. Berger, "Progressive multifocal leukoencephalopathy and newer biological agents," Drug Safety, vol. 33, no. 11, pp. 969983, 2010.

[14] J. R. Berger, B. Kaszovitz, M. J. D. Post, and G. Dickinson, "Progressive multifocal leukoencephalopathy associated with human immunodeficiency virus infection: a review of the literature with a report of sixteen cases," Annals of Internal Medicine, vol. 107, no. 1, pp. 78-87, 1987.

[15] I. J. Koralnik, C. Wüthrich, X. Dang et al., "JC virus granule cell neuronopathy: a novel clinical syndrome distinct from progressive multifocal leukoencephalopathy," Annals of Neurology, vol. 57, no. 4, pp. 576-580, 2005.

[16] J. F. Viallard, E. Ellie, E. Lazaro, M. E. Lafon, and J. L. Pellegrin, "JC virus meningitis in a patient with systemic lupus erythematosus," Lupus, vol. 14, no. 12, pp. 964-966, 2005.

[17] K. Blake, D. Pillay, W. Knowles, D. W. G. Brown, P. D. Griffiths, and B. Taylor, "JC virus associated meningoencephalitis in an immunocompetent girl," Archives of Disease in Childhood, vol. 67, no. 7, pp. 956-957, 1992.

[18] A. Behzad-Behbahani, P. E. Klapper, P. J. Vallely, G. M. Cleator, and A. Bonington, "BKV-DNA and JCV-DNA in CSF of patients with suspected meningitis or encephalitis," Infection, vol. 31, no. 6, pp. 374-378, 2003.

[19] P. Fontoura, J. Vale, C. Lima, F. Scaravilli, and J. Guimarães, "Progressive myoclonic ataxia and JC virus encephalitis in an AIDS patient," Journal of Neurology Neurosurgery and Psychiatry, vol. 72, no. 5, pp. 653-656, 2002.

[20] E. C. Tallantyre, S. M. L. Paine, C. P. Sharp, J. S. Lowe, and B. Gran, "Atypical progressive multifocal leukoencephalopathy associated with an unusual JC polyomavirus mutation," Archives of Neurology, vol. 66, no. 8, pp. 1021-1024, 2009.

[21] M. I. Husseiny, B. Anastasi, J. Singer, and S. F. Lacey, "A comparative study of Merkel cell, BK and JC polyomavirus infections in renal transplant recipients and healthy subjects," Journal of Clinical Virology, vol. 49, no. 2, pp. 137-140, 2010.

[22] C. B. Drachenberg, H. H. Hirsch, J. C. Papadimitriou et al., "Polyomavirus BK versus JC replication and nephropathy in renal transplant recipients: a prospective evaluation," Transplantation, vol. 84, no. 3, pp. 323-330, 2007.

[23] V. López, C. Gutiérrez, D. Burgos et al., "Prospective study of infection and nephropathy due to BK and JC polyomavirus in 76 kidney transplant recipients," Transplantation Proceedings, vol. 40, no. 9, pp. 2927-2929, 2008.

[24] I. Helanterä, F. Ortiz, E. Auvinen et al., "Polyomavirus BK and JC infections in well matched Finnish kidney transplant 
recipients," Transplant International, vol. 22, no. 7, pp. 688-693, 2009.

[25] W. Y. Yin, M. C. Lu, M. C. Lee, S. C. Liu, T. Y. Lin, and N. S. Lai, "A correlation between polyomavirus JC virus quantification and genotypes in renal transplantation," American Journal of Surgery, vol. 200, no. 1, pp. 53-58, 2010.

[26] V. Lopez, C. Gutierrez, E. Sola et al., "Does JC polyomavirus cause nephropathy in renal transplant patients?" Transplantation Proceedings, vol. 42, no. 8, pp. 2889-2891, 2010.

[27] J. H. Hu, H. Zhao, Y. P. Huang et al., "Opportunistic posttransplantation virus infections in renal transplant recipients," Transplantation Proceedings, vol. 43, no. 10, pp. 3715-3719, 2011.

[28] E. P. Pires, C. V. Bernardino-Vallinoto, D. M. Alves et al., "Prevalence of infection by JC and BK polyomaviruses in kidney transplant recipients and patients with chronic renal disease," Transplant Infectious Disease, vol. 13, no. 6, pp. 633-637, 2011.

[29] C. Mengelle, N. Kamar, J. M. Mansuy et al., "JC virus DNA in the peripheral blood of renal transplant patients: a 1-year prospective follow-up in France," Journal of Medical Virology, vol. 83, no. 1, pp. 132-136, 2011.

[30] S. Taheri, F. Kafilzadeh, M. Shafa et al., "Comparison of polyomavirus (BK virus and JC viruses) viruria in renal transplant recipients with and without kidney dysfunction," Journal of Research in Medical Sciences, vol. 16, no. 7, pp. 916-922, 2011.

[31] B. K. Saundh, S. Tibble, R. Baker, K. Sasnauskas, M. Harris, and A. Hale, "Different patterns of BK and JC polyomavirus reactivation following renal transplantation," Journal of Clinical Pathology, vol. 63, no. 8, pp. 714-718, 2010.

[32] S. D. Gardner, "Implication of papovaviruses in human diseases," in Comparative Diagnosis of Viral Disease, I. Human and Related Viruses, E. Kurstak and C. Kurstak, Eds., part A, chapter 3, pp. 41-84, Academic Press, New York, NY, USA, 1977.

[33] T. F. Hogan, E. C. Borden, and J. A. McBain, "Human polyomavirus infections with $\mathrm{JC}$ virus and BK virus in renal transplant patients," Annals of Internal Medicine, vol. 92, no. 3, pp. 373-378, 1980.

[34] S. D. Gardner, E. F. D. Mackenzie, C. Smith, and A. A. Porter, "Prospective study of the human polyomavirus BK and JC and cytomegalovirus in renal transplant recipients," Journal of Clinical Pathology, vol. 37, no. 5, pp. 578-586, 1984.

[35] P. Randhawa, J. Uhrmacher, W. Pasculle et al., "A comparative study of BK and JC virus infections in organ transplant recipients," Journal of Medical Virology, vol. 77, no. 2, pp. 238-243, 2005.

[36] S. Delbue, M. Ferraresso, F. Elia et al., "Investigation of polyomaviruses replication in pediatric patients with nephropathy receiving rituximab," Journal of Medical Virology, vol. 84, no. 9, pp. 1464-1470, 2012.

[37] F. K. Baksh, S. D. Finkelstein, P. A. Swalsky, G. L. Stoner, C. F. Ryschkewitsch, and P. Randhawa, "Molecular genotyping of BK and JC viruses in human polyomavirus-associated interstitial nephritis after renal transplantation," American Journal of Kidney Diseases, vol. 38, no. 2, pp. 354-365, 2001.

[38] R. R. Razonable, R. A. Brown, A. Humar, E. Covington, E. Alecock, and C. V. Paya, "A longitudinal molecular surveillance study of human polyomavirus viremia in heart, kidney, liver, and pancreas transplant patients," Journal of Infectious Diseases, vol. 192, no. 8, pp. 1349-1354, 2005.

[39] S. Kusne, R. A. Vilchez, P. Zanwar et al., "Polyomavirus JC urinary shedding in kidney and liver transplant recipients associated with reduced creatinine clearance," Journal of Infectious Diseases, vol. 206, no. 6, pp. 875-880, 2012.
[40] F. Brinkert, A. Briem-Richter, C. Ilchmann, M. J. Kemper, and R. Ganschow, "Prevalence of polyomavirus viruria (JC virus/BK virus) in children following liver transplantation," Pediatric Transplantation, vol. 14, no. 1, pp. 105-108, 2010.

[41] P. Muñoz, M. Fogeda, E. Bouza, E. Verde, J. Palomo, and R. Bañares, "Prevalence of BK virus replication among recipients of solid organ transplants," Clinical Infectious Diseases, vol. 41, no. 12, pp. 1720-1725, 2005.

[42] K. E. Doucette, X. L. Pang, K. Jackson et al., "Prospective monitoring of bk polyomavirus infection early posttransplantation in nonrenal solid organ transplant recipients," Transplantation, vol. 85, no. 12, pp. 1733-1736, 2008.

[43] A. Antonsson, M. Pawlita, M. C. Feltkamp et al., "Longitudinal study of seroprevalence and serostability of the human polyomaviruses JCV and BKV in organ transplant recipients," Journal of Medical Virology, vol. 85, no. 2, pp. 327-335, 2013.

[44] N. Kamar, C. Mengelle, and L. Rostaing, "Incidence of JC-virus replication after rituximab therapy in solid-organ transplant patients," American Journal of Transplantation, vol. 9, no. 1, pp. 244-245, 2009.

[45] L. D. Thomas, R. A. Vilchez, Z. S. White et al., "A prospective longitudinal study of polyomavirus shedding in lung-transplant recipients," Journal of Infectious Diseases, vol. 195, no. 3, pp. 442449, 2007.

[46] C. D. Crowder, K. A. Gyure, C. B. Drachenberg et al., "Successful outcome of progressive multifocal leukoencephalopathy in a renal transplant patient," American Journal of Transplantation, vol. 5, no. 5, pp. 1151-1158, 2005.

[47] J. K. Hix, W. E. Braun, and C. M. Isada, "Delirium in a renal transplant recipient associated with $\mathrm{BK}$ virus in the cerebrospinal fluid," Transplantation, vol. 78, no. 9, pp. 14071408, 2004.

[48] L. Cabrejo, M. Diop, A. Blohorn-Sense, and B. Mihout, "Progressive BK virus associated multifocal leukoencephalopathy in an immunocompromised patient treated with corticosteroids," Revue Neurologique, vol. 161, no. 3, pp. 326-330, 2005.

[49] V. Nickeleit, H. H. Hirsch, M. Zeiler et al., "BK-virus nephropathy in renal transplants-tubular necrosis, MHC-class II expression and rejection in a puzzling game," Nephrology Dialysis Transplantation, vol. 15, no. 3, pp. 324-332, 2000.

[50] V. Nickeleit, H. K. Singh, and M. J. Mihatsch, "Polyomavirus nephropathy: morphology, pathophysiology, and clinical management," Current Opinion in Nephrology and Hypertension, vol. 12, no. 6, pp. 599-605, 2003.

[51] M. Mengel, M. Marwedel, J. Radermacher et al., "Incidence of polyomavirus-nephropathy in renal allografts: influence of modern immunosuppressive drugs," Nephrology Dialysis Transplantation, vol. 18, no. 6, pp. 1190-1196, 2003.

[52] D. L. Bohl, G. A. Storch, C. Ryschkewitsch et al., "Donor origin of BK virus in renal transplantation and role of HLA C7 in susceptibility to sustained BK viremia," American Journal of Transplantation, vol. 5, no. 9, pp. 2213-2221, 2005.

[53] H. H. Hirsch and J. Steiger, "Polyomavirus BK," Lancet Infectious Diseases, vol. 3, no. 10, pp. 611-623, 2003.

[54] H. H. Hirsch, "Polyomavirus BK nephropathy: a (re-)emerging complication in renal transplantation," American Journal of Transplantation, vol. 2, no. 1, pp. 25-30, 2002.

[55] P. Randhawa, F. Baksh, N. Aoki, D. Tschirhart, and S. Finkelstein, "JC virus infection in allograft kidneys: analysis by polymerase chain reaction and immunohistochemistry," Transplantation, vol. 71, no. 9, pp. 1300-1303, 2001. 
[56] A. Kazory, D. Ducloux, J. M. Chalopin, R. Angonin, B. Fontanière, and H. Moret, "The first case of JC virus allograft nephropathy," Transplantation, vol. 76, no. 11, pp. 1653-1655, 2003.

[57] M. C. Wen, C. L. Wang, M. Wang et al., "Association of JC virus with tubulointerstitial nephritis in a renal allograft recipient," Journal of Medical Virology, vol. 72, no. 4, pp. 675-678, 2004.

[58] K. Dörries and V. Ter Meulen, "Progressive multifocal leucoencephalopathy: detection of papovavirus JC in kidney tissue," Journal of Medical Virology, vol. 11, no. 4, pp. 307-317, 1983.

[59] G. Kantarci, Z. Eren, A. Demirağ, I. Dogan, F. Çakalagaoglu, and G. Yilmaz, "JC virus-associated nephropathy in a renal transplant recipient and comparative analysis of previous cases," Transplant Infectious Disease, vol. 13, no. 1, pp. 89-92, 2011.

[60] C. Polo, J. L. Pérez, A. Mielnichuck, C. G. Fedele, J. Niubó, and A. Tenorio, "Prevalence and patterns of polyomavirus urinary excretion in immunocompetent adults and children," Clinical Microbiology and Infection, vol. 10, no. 7, pp. 640-644, 2004.

[61] A. Rossi, S. Delbue, R. Mazziotti et al., "Presence, quantitation and characterization of JC virus in the urine of Italian immunocompetent subjects," Journal of Medical Virology, vol. 79, no. 4, pp. 408-412, 2007.

[62] T. Kitamura, Y. Yogo, T. Kunitake, K. Suzuki, A. Tajima, and K. Kawabe, "Effect of immunosuppression on the urinary excretion of $\mathrm{BK}$ and JC polyomaviruses in renal allograft recipients," International Journal of Urology, vol. 1, no. 1, pp. 2832, 1994.

[63] P. Randhawa, A. Vats, and R. Shapiro, "Monitoring for polyomavirus BK and JC in urine: comparison of quantitative polymerase chain reaction with urine cytology," Transplantation, vol. 79, no. 8, pp. 984-986, 2005.

[64] I. Binet, V. Nickeleit, H. H. Hirsch et al., "Polyomavirus disease under new immunosuppressive drugs: a cause of renal graft dysfunction and graft loss," Transplantation, vol. 67, no. 6, pp. 918-922, 1999.

[65] A. Behzad-Behbahani, P. E. Klapper, P. J. Vallely, G. M. Cleator, and S. H. Khoo, "Detection of BK virus and JC virus DNA in urine samples from immunocompromised (HIV-infected) and immunocompetent (HIV-non-infected) patients using polymerase chain reaction and microplate hybridisation," Journal of Clinical Virology, vol. 29, no. 4, pp. 224-229, 2004.

[66] A. Kazory and D. Ducloux, "Renal transplantation and polyomavirus infection: recent clinical facts and controversies," Transplant Infectious Disease, vol. 5, no. 2, pp. 65-71, 2003.

[67] K. Doerries, "Human polyomavirus JC and BK persistent infection," Advances in Experimental Medicine and Biology, vol. 577, pp. 102-116, 2006.

[68] W. A. Knowles, "Discovery and epidemiology of the human polyomaviruses BK virus (BKV) and JC virus (JCV)," Advances in Experimental Medicine and Biology, vol. 577, pp. 19-45, 2006.

[69] T. Phillips, R. Jacobs, and E. N. Ellis, "Polyoma nephropathy and progressive multifocal leukoencephalopathy in a renal transplant recipient," Journal of Child Neurology, vol. 19, no. 4, pp. 301-304, 2004.

[70] F. J. Mateen, R. Muralidharan, M. Carone et al., "Progressive multifocal leukoencephalopathy in transplant recipients," Annals of Neurology, vol. 70, no. 2, pp. 305-322, 2011.

[71] N. Kamar, O. Milioto, B. Puissant-Lubrano et al., "Incidence and predictive factors for infectious disease after rituximab therapy in kidney-transplant patients," American Journal of Transplantation, vol. 10, no. 1, pp. 89-98, 2010.
[72] L. Rinaldi, F. Rinaldi, P. Perini et al., "No evidence of JC virus reactivation in natalizumab treated multiple sclerosis patients: an 18 month follow-up study," Journal of Neurology, Neurosurgery and Psychiatry, vol. 81, no. 12, pp. 1345-1350, 2010.

[73] C. Warnke, T. Menge, H. P. Hartung et al., "Natalizumab and progressive multifocal leukoencephalopathy: what are the causal factors and can it be avoided?" Archives of Neurology, vol. 67, no. 8, pp. 923-930, 2010.

[74] X. S. Cheng, D. L. Bohl, G. A. Storch et al., "Inhibitory interactions between BK and JC virus among kidney transplant recipients," Journal of the American Society of Nephrology, vol. 22, no. 5, pp. 825-831, 2011.

[75] H. H. Hirsch, W. Knowles, M. Dickenmann et al., "Prospective study of polyomavirus type BK replication and nephropathy in renal-transplant recipients," New England Journal of Medicine, vol. 347, no. 7, pp. 488-496, 2002. 


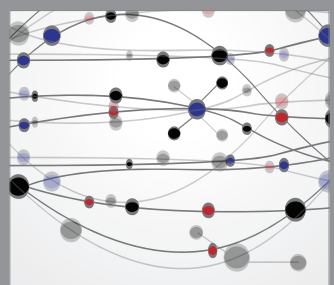

The Scientific World Journal
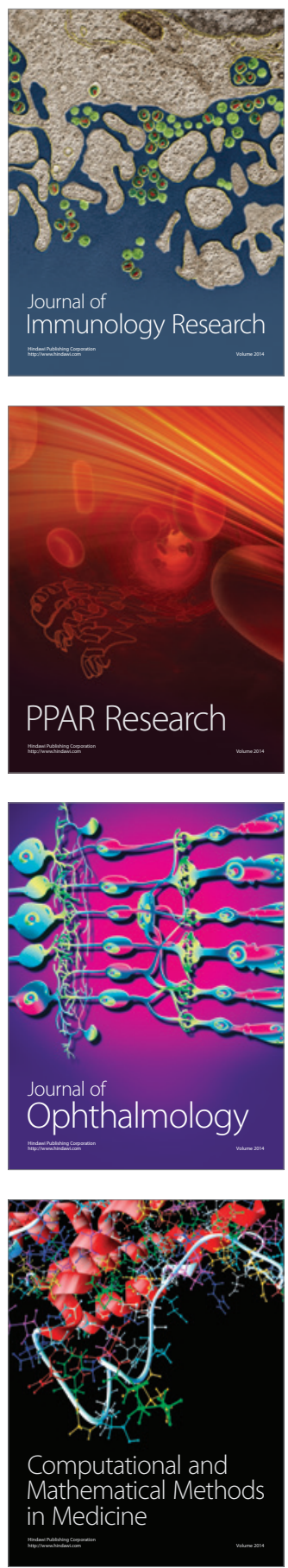

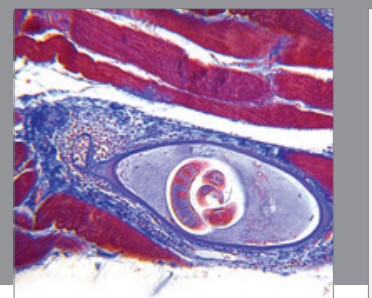

Gastroenterology

Research and Practice
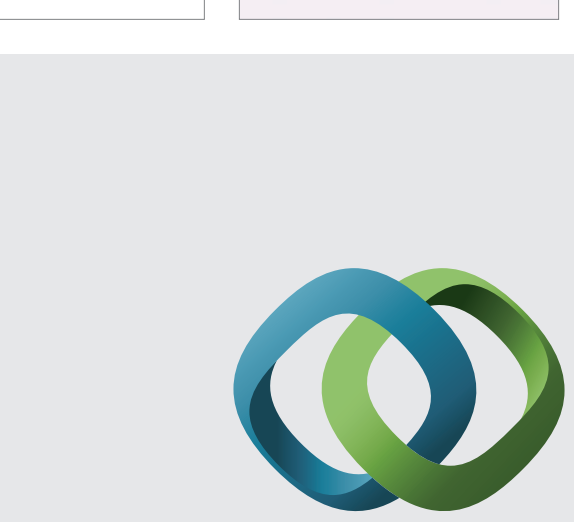

\section{Hindawi}

Submit your manuscripts at

http://www.hindawi.com
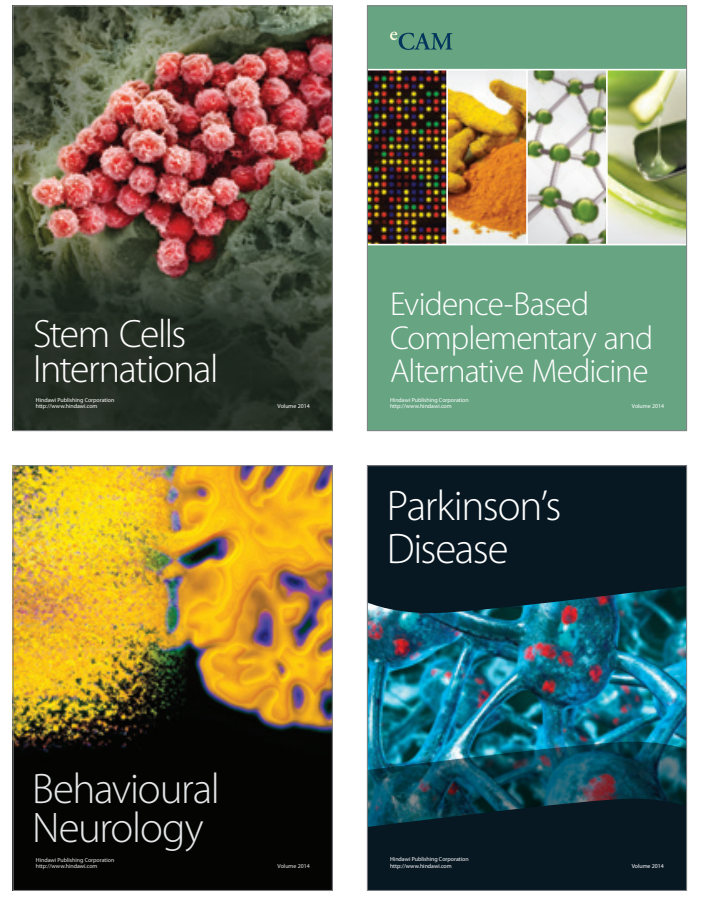
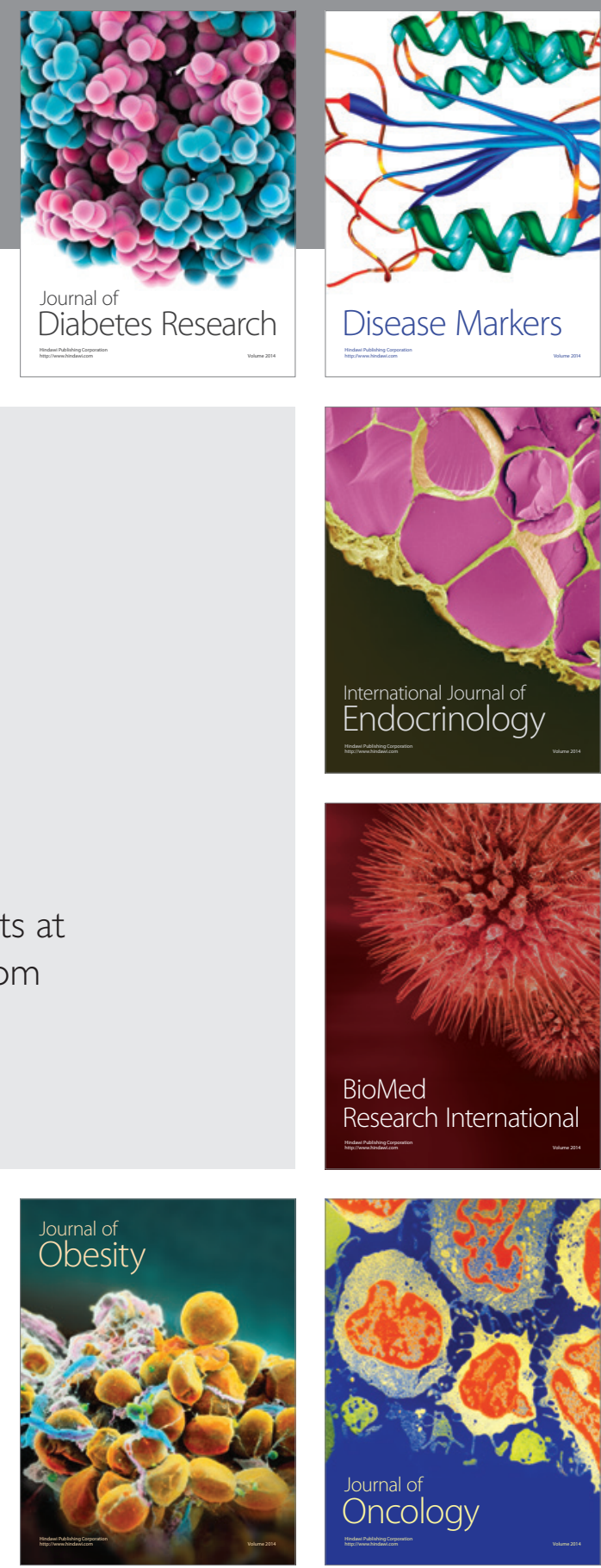

Disease Markers
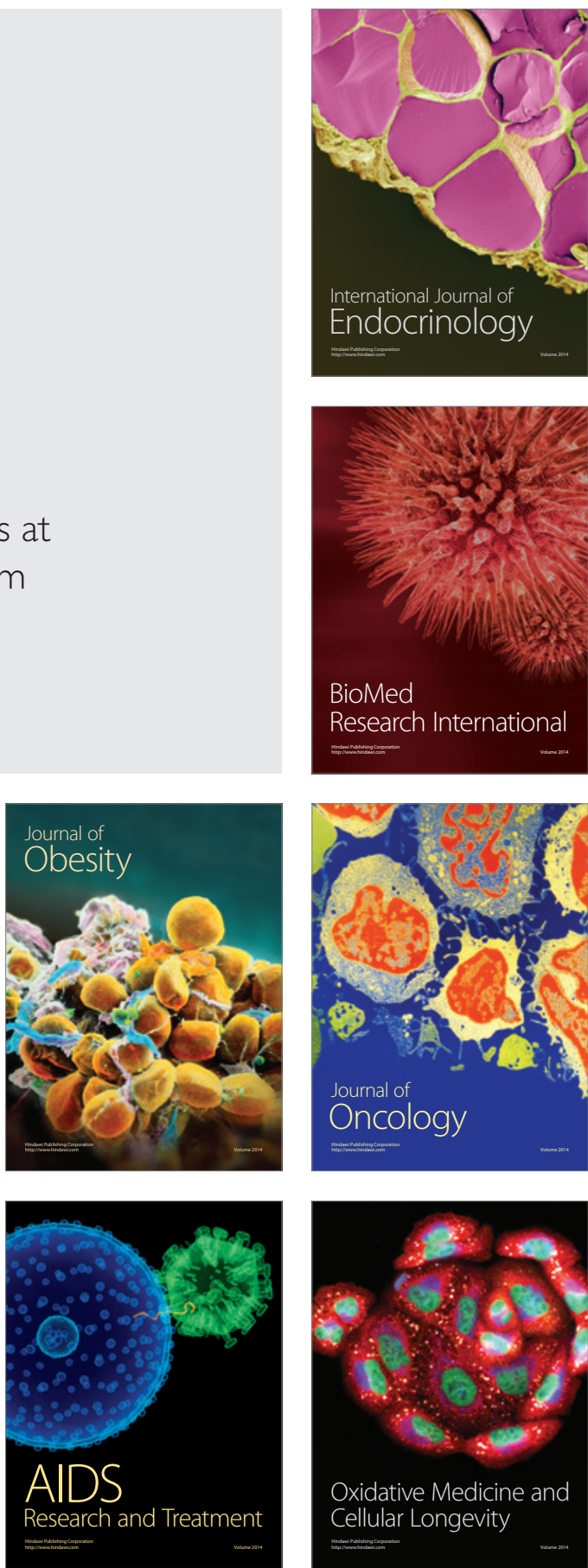